\title{
Introduction of special issue "Advances in Microsurgery for Upper and Lower Extremity Reconstruction and Limb Preservation"
}

\author{
Matthew L. Iorio \\ Division of Plastic and Reconstructive Surgery, University of Colorado Anschutz Medical Center, Aurora, CO 80045, USA.
}

Correspondence to: Dr. Matthew L. Iorio, Division of Plastic and Reconstructive Surgery, University of Colorado Anschutz Medical Center, Aurora, CO 80045, USA.E-mail: mattiorio@gmail.com

How to cite this article: Iorio ML. Introduction of special issue "Advances in Microsurgery for Upper and Lower Extremity Reconstruction and Limb Preservation". Plast Aesthet Res 2020;7:22. http://dx.doi.org/10.20517/2347-9264.2020.86

Received: 17 Apr 2020 Accepted: 20 Apr 2020 Published: 29 Apr 2020

Science Editor: Raúl González-García Copy Editor: Jing-Wen Zhang Production Editor: Jing Yu

I am honored to present the special edition "Advances in Microsurgery for Upper and Lower Extremity Reconstruction and Limb Preservation" for Plastic and Aesthetic Research. Herein, world-class experts describe their techniques for functional reconstruction and rehabilitation in extremity injuries and limb salvage.

The goal of this edition was to provide a comprehensive reference for the extremity surgeon. These outstanding articles review not only individual techniques of flap coverage, such as chimeric and propeller flaps, but also the unique considerations for flap reconstruction timing, tendon reconstruction, techniques for perforator mapping and postoperative monitoring, and the importance of the plastic surgeon in mass casualty incidents. And as such, a significant improvement in the functional quotient can be seen through the use of vascularized bone grafting, composite allotransplantation, and functional muscle and nerve reconstructions.

Reconstructive surgeons are often asked for assistance to "close a wound" in patients with complex limb defects. This reductive approach belies a greater opportunity to enhance limb salvage through improving functional outcomes. Although it may stem from a lack of understanding of available options or from the mindset that complex reconstructions may have a lower chance of success, a truer definition of success should be restoring the patient to as close to the pre-injury state as possible. To fulfil our commitment to our patients, we must advocate for sophisticated and innovative reconstruction, demonstrating improved outcomes by return to functional baselines, ambulation, and decreased pain.

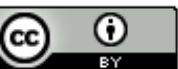

(C) The Author(s) 2020. Open Access This article is licensed under a Creative Commons Attribution 4.0 International License (https://creativecommons.org/licenses/by/4.0/), which permits unrestricted use, sharing, adaptation, distribution and reproduction in any medium or format, for any purpose, even commercially, as long as you give appropriate credit to the original author(s) and the source, provide a link to the Creative Commons license, and indicate if changes were made.

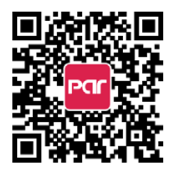


Limb salvage is a multidisciplinary specialty, not only from the surgical perspective but also in the application of the reconstruction. Critical checkpoints include overall patient safety and trauma resuscitation, prioritization of salvage, and tailored options for reconstruction, all of which are paramount at a time when decision-making may be limited by a lack of resources as well as the sheer volume of patient needs. Reconstruction should proceed in an orderly and timely manner, not only from the initial stage but with contemplation of the secondary, tertiary, or even quaternary interventions that may be considered down the road. This concept is frequently seen in the setting of long bone fractures, which may require secondary bone grafting, external-fixator placement, and distraction osteogenesis. This edition attempts to integrate those concepts across extremity microsurgery, in cases such as combined tendon reconstruction, targeted muscle reinnervation, and functional muscle transfers.

Lastly, an area of care that can be overlooked at the detriment of the overall result concerns post-reconstructive orthotic assist devices. These are relevant both in choosing a stable, durable and appropriately shaped soft tissue reconstruction, but also in understanding the additional gains afforded by a well-designed prosthesis. With an understanding of these adaptive devices, a reconstruction can be better tailored to optimize outcomes, including a reference for various levels of amputation, as well as a guide for soft tissue tailoring to prevent fitment or wound durability complications.

Thanks to all of the authors, and also the reviewers and editorial staff from Plastic and Aesthetic Research, for making this an exceptional issue and contribution to the field of extremity microsurgery.

I hope that you find this special edition useful, and an active guide to extremity reconstruction.

\section{DECLARATIONS}

\section{Authors' contributions}

The author contributed solely to the article.

\section{Availability of data and materials}

Not applicable.

\section{Financial support and sponsorship}

None.

\section{Conflicts of interest}

The author declared that there are no conflicts of interest.

\section{Ethical approval and consent to participate}

Not applicable.

\section{Consent for publication}

Not applicable.

\section{Copyright}

(c) The Author(s) 2020. 